on $\mathrm{CO}_{2}$ emissions ${ }^{10}$. On the other hand, top emitters have achieved some success in exploring alternative platforms for climate change diplomacy outside the United Nations Framework Convention on Climate Change $^{11}$. The more focused dialogues, such as the US-China bilateral talk and the G20 forum, have the potential to complement the unwieldy United Nations-led process.

However, China's participation in a new HFC agreement still faces many obstacles. For the fluorine chemical industry, although NAP allows China to increase production up to 2018, the HFC production lines have to retire gradually after 2025. As they lack indigenous technologies, domestic chemical companies are reluctant to make early moves. For the air conditioning and refrigeration industry, low-GWP alternatives are generally more expensive, which raises concern that the manufacturing sector may become less competitive. For the HFC-23 by-product emissions controls, the rate of subsidy of the Multilateral Fund is likely to be much lower than that of the CDM carbon market. The HCFC-22 production facilities have less incentive to capture and destroy HFC-23 under the Montreal Protocol.

We address the above concerns with the following points. First, the Multilateral Fund can assist in financing the conversion of the existing manufacturing processes, technology transfer and capacity building. Second, most HFC production capacity is flexible enough to produce non-HFC chemicals, which lowers the cost of switching. Third, whether or not China joins in an HFC agreement, developed countries' embargo of HFCs will eventually eliminate the international demand for China's HFC exports. Fourth, the sooner the domestic firms start to develop low-GWP substitutes, the better the chance they will avoid being locked into a high-GWP HFC production and consumption economy. Last, but not least, the remarkably generous subsidy for HFC-23 incineration by carbon emissions reduction credits is not sustainable, which has already been addressed by the CDM executive board.

Reducing HFC emissions is a costeffective option for China to contribute to the global climate target that limits temperature increase to $2{ }^{\circ} \mathrm{C}$ above preindustrial levels. A study shows that China is unlikely to achieve the Copenhagen commitment to slash its carbon intensity by $40-45 \%$ by 2020 relative to the 2005 level without further mitigation effort ${ }^{4}$. A phase-down of HFCs is an economically viable way of compliance as it affects a small number of sectors with moderate costs. In addition, switching to some cooling and insulation technologies without refrigerants ('not-in-kind' alternatives) can reduce not only HFCs, but also $\mathrm{CO}_{2}$ emissions from energy consumption.

Eliminating HFCs is also associated with political benefits. As the world's top greenhouse gas emitter, China has been under mounting pressure in international climate negotiations. Although China has taken domestic actions to slow down emissions growth, it is questioned frequently for its incongruous international commitment. An active participation in the phase-down of HFCs will alleviate China's diplomatic pressure on climate change. Furthermore, while China and the United States are competing on many fronts, HFC phase-down can be a promising area of collaboration for both countries to build mutual political trust and improve diplomatic relations.

Junjie Zhang is at the School of International Relations and Pacific Studies, University of California, San Diego, 9500 Gilman Drive \#0519, La Jolla, California 92093-0519, USA. Can Wang is at the School of Environment and Center for Earth System Science, Tsinghua University, Beijing 100084, China.

e-mail: junjiezhang@ucsd.edu

References

1. Velders, G. J. M. et al. Science 335, 922-923 (2012).

2. United Nations Environment Programme HFCs: A Critical Link in Protecting Climate and the Ozone Layer (UNEP, 2011); http://www.unep.org/dewa/Portals/67/pdf/HFC_report.pd

3. Velders, G. J. M., Fahey, D. W., Daniel, J. S., McFarland, M. \& Andersen, S. O. Proc. Natl Acad. Sci. USA 106, 10949-10954 (2009).

4. Yang, Y., Zhang, J. \& Wang, C. Is China on Track to Comply with its 2020 Copenhagen Carbon Intensity Commitment? (UC San Diego, 2014); www.escholarship.org/uc/item/1r5251g8

5. United Nations Environment Programme Proposed Amendment to the Montreal Protocol Submitted by Canada, Mexico and the United States of America UNEP/OzL.Pro.WG.1/33/3 (UNEP, 2013); http://go.nature.com/C6nghj

6. Institute for Governance and Sustainable Development Support for Montreal Protocol Amendment Grows with Commitments by Leaders at the Highest Levels of Government (IGSD, 2013); http://www.igsd.org/news/documents/OzoNewsarticle.pdf

7. Lin, H., Cui, Y-L. \& Yang, L-R. Adv. Clim. Change Res. 4, 260-266 (2013)

8. Wara, M. Nature 445, 595-596 (2007).

9. Zhang, J. \& Wang, C. J. Environ. Econ. Manag. 62, 140-154 (2011).

10. Xu, Y., Zaelke, D., Velders, G. J. M \& Ramanathan, V. Atmos. Chem. Phys. 13, 6083-6089 (2013).

11. Bi, J. et al. Glob. Environ. Change 24, 2-4 (2014).

Acknowledgements

This study is supported by the National Natural Science Foundation of China (NO.71273153). We thank J. Lin for excellent research assistance.

Additional information

Supplementary information is available in the online version of the paper.

\title{
The global groundwater crisis
}

\section{J. S. Famiglietti}

\section{Groundwater depletion the world over poses a far greater threat to global water security than is currently acknowledged.}

G roundwater - the water stored beneath Earth's surface in soil and porous rock aquifers - accounts for as much as $33 \%$ of total water withdrawals worldwide ${ }^{1}$. Over two billion people rely on groundwater as their primary water source ${ }^{2}$, while half or more of the irrigation water used to grow the world's food is supplied from underground sources ${ }^{1}$.

Groundwater also acts as the key strategic reserve in times of drought ${ }^{3}$, in particular during prolonged events such as those in progress across the western United States (Fig. 1), northeastern Brazil and Australia. Like money in the bank, groundwater sustains societies through the lean times of little incoming rain and snow. Hence, without a sustainable groundwater 


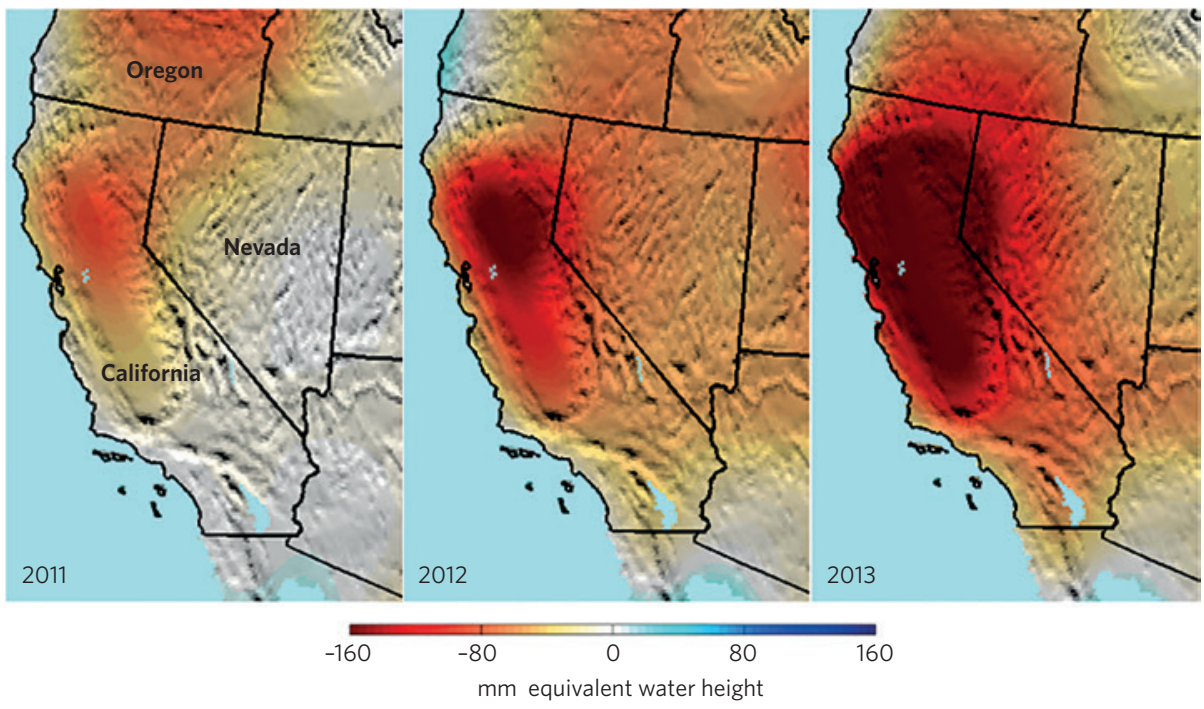

Figure 1 | NASA's Gravity Recovery and Climate Experiment (GRACE) satellite mission is providing new, space-based insights into the global nature of groundwater depletion ${ }^{3-5}$. The ongoing California drought is evident in these maps of dry season (September-November) total water storage anomalies (in mm equivalent water height; anomalies with respect to 2005-2010) in the western United States. The maps were constructed using GRACE Mascons solutions from NASA's Jet Propulsion Laboratory (M. M. Watkins, D. N. Wiese, D.-N. Yuan, C. Boening and F. W. Landerer, unpublished results). California's Sacramento and San Joaquin river basins have lost roughly $15 \mathrm{~km}^{3}$ of total water per year since 2011 more water than all 38 million Californians use for domestic and municipal supplies annually — over half of which is due to groundwater pumping in the Central Valley ${ }^{3,5}$. Image: Felix W. Landerer, NASA Jet Propulsion Laboratory, California Institute of Technology, USA.

reserve, global water security is at far greater risk than is currently recognized.

The irony of groundwater is that despite its critical importance to global water supplies, it attracts insufficient management attention relative to more visible surface water supplies in rivers and reservoirs. In many regions around the world, groundwater is often poorly monitored and managed. In the developing world, oversight is often non-existent ${ }^{4,5}$.

The result has been a veritable groundwater 'free for all': property owners who can afford to drill wells generally have unlimited access to groundwater. Some countries, such as India, for example, even subsidize electricity costs for pumping to encourage greater agricultural productivity ${ }^{6}$ at the expense of falling aquifer levels.

Consequently, most of the major aquifers in the world's arid and semi-arid zones, that is, in the dry parts of the world that rely most heavily on groundwater, are experiencing rapid rates of groundwater depletion $^{7-9}$ (Table 1). Groundwater is being pumped at far greater rates than it can be naturally replenished, so that many of the largest aquifers on most continents are being mined, their precious contents never to be returned. These include the North China Plain ${ }^{10}$, Australia's Canning Basin, the Northwest Sahara Aquifer System, the Guarani Aquifer in South America, the High Plains ${ }^{11}$ and Central Valley ${ }^{3}$ aquifers of the United States, and the aquifers beneath northwestern India ${ }^{4}$ and the Middle East ${ }^{12}$ (Fig. 2). Nearly all of these underlie the word's great agricultural regions and are primarily responsible for their high productivity.

Climate change and associated changes to the water cycle vastly complicate the challenge of sustaining groundwater supplies for the foreseeable future. Changing patterns of precipitation and groundwater recharge, and increasing extremes of flooding and drought ${ }^{13}$ are among the most palpable impacts of global change, and underscore the need to rethink stationarity in current water management strategies ${ }^{14}$. As the wet, high- and lowlatitude areas of the world become wetter, and the dry areas in between become drier ${ }^{15}$ (and already limited groundwater recharge decreases), the 'haves' and 'have nots' of the future water landscape are emerging.

Moreover, because the natural human response to drought is to pump more groundwater ${ }^{3,5,12}$, continued groundwater depletion will very likely accelerate midlatitude drying, a problem that will be exacerbated by significant population growth in the same regions.

The environmental consequences of groundwater depletion extend well beyond decreasing freshwater availability. As groundwater levels drop, wells run dry and must be dug to deeper levels. Groundwater quality decreases, and the cost of pumping water from greater depths increases ${ }^{7}$. Inequity issues arise because only the relatively wealthy can bear the expense of digging deeper wells, paying greater energy costs to pump groundwater

Table 1 | Annual rates of groundwater depletion in the major aquifers of Earth's arid and semi-arid mid-latitudes.

\begin{tabular}{|c|c|c|c|c|c|}
\hline \multirow[t]{2}{*}{ Aquifer } & \multirow[t]{2}{*}{ Country } & \multicolumn{2}{|c|}{ Estimated recent depletion rates } & \multirow[t]{2}{*}{ Time period } & \multirow[t]{2}{*}{ Reference } \\
\hline & & $\left(\mathrm{mm} \mathrm{yr} r^{-1}\right)$ & $\left(\mathrm{km}^{3} \mathrm{yr}^{-1}\right)$ & & \\
\hline Northwest Sahara & Algeria, Libya, Tunisia & 2.8 & 2.7 & 2003-2013 & 18 \\
\hline California Central Valley & USA & 20.4 & 3.1 & $2003-2010$ & 3 \\
\hline High Plains (Ogallala) & USA & 27.6 & 12.5 & 2003-2013 & 11 \\
\hline Guarani & Argentina, Brazil, Paraguay, Uruguay & 0.6 & 1.0 & 2003-2009 & 18 \\
\hline Northern Middle East & Iran, Iraq, Syria, Turkey & 17.3 & 13.0 & 2003-2009 & 12 \\
\hline Arabian & Iraq, Jordan, Oman, Qatar, Saudi Arabia, UAE, Yemen & 9.1 & 15.5 & 2003-2013 & 18 \\
\hline Northwestern India & India, Pakistan & 40.0 & 17.7 & $2002-2008$ & 4 \\
\hline North China Plain & China & 22.0 & 8.3 & 2003-2010 & 10 \\
\hline Canning Basin & Australia & 9.4 & 3.60 & 2003-2013 & 18 \\
\hline
\end{tabular}

All rates derived from the NASA GRACE satellite mission. 
from increased depths and treating the lower-quality water that is often found deeper within aquifers. Land surface subsidence, seawater intrusion, sea-level rise, streamflow depletion, loss of springs, wetlands and ecological damages ${ }^{7}$, and regional climate feedbacks from irrigation are other unintended consequences of groundwater depletion.

Understanding why the deterioration of global groundwater supplies has occurred may be the first step towards their future maintenance. Rapid, unchecked population growth and rising quality of life, along with increasing demand for food and energy, all contribute to far greater levels of stress on limited groundwater resources ${ }^{7-9}$.

Another factor is that most water law and policy in the developed world was written a century or more ago, when the tight interconnections between surface water and groundwater were poorly appreciated ${ }^{16}$.

Similarly, the evolving understanding of human-driven climate change is a relatively recent phenomenon ${ }^{17}$, and one that only now is beginning to impact regional and national water management decisions ${ }^{5,14}$. In short, the need to include groundwater in a holistic water management framework that recognizes future decreases in renewable surface water in Earth's arid and semi-arid latitudes has only recently become clear ${ }^{16}$.

While reversing climate change and its impact on groundwater resources is no longer a possibility for humanity, managing our way through the global groundwater crisis is. There are several essential steps that warrant immediate, international attention.

The first is recognition and acceptance that in many parts of the world, in particular in the dry, mid-latitudes, far more water is used than is available on an annual, renewable basis. Precipitation, snowmelt and streamflow are no longer enough to supply the multiple, competing demands for society's water needs ${ }^{7-9}$. Because the gap between supply and demand is routinely bridged with non-renewable groundwater, even more so during drought, groundwater supplies in some major aquifers will be depleted in a matter of decades ${ }^{3,10-12}$. The myth of limitless water and the free-for-all mentality that has pervaded groundwater use must now come to an end.

Implicit in this first step is the need for far greater agricultural water use efficiency. Agriculture accounts for nearly $80 \%$ of water use globally, and as stated above, at least half of the irrigation water used is groundwater ${ }^{1}$. Even modest gains in agricultural efficiency will result in tremendous volumes of groundwater saved, or of water available for the

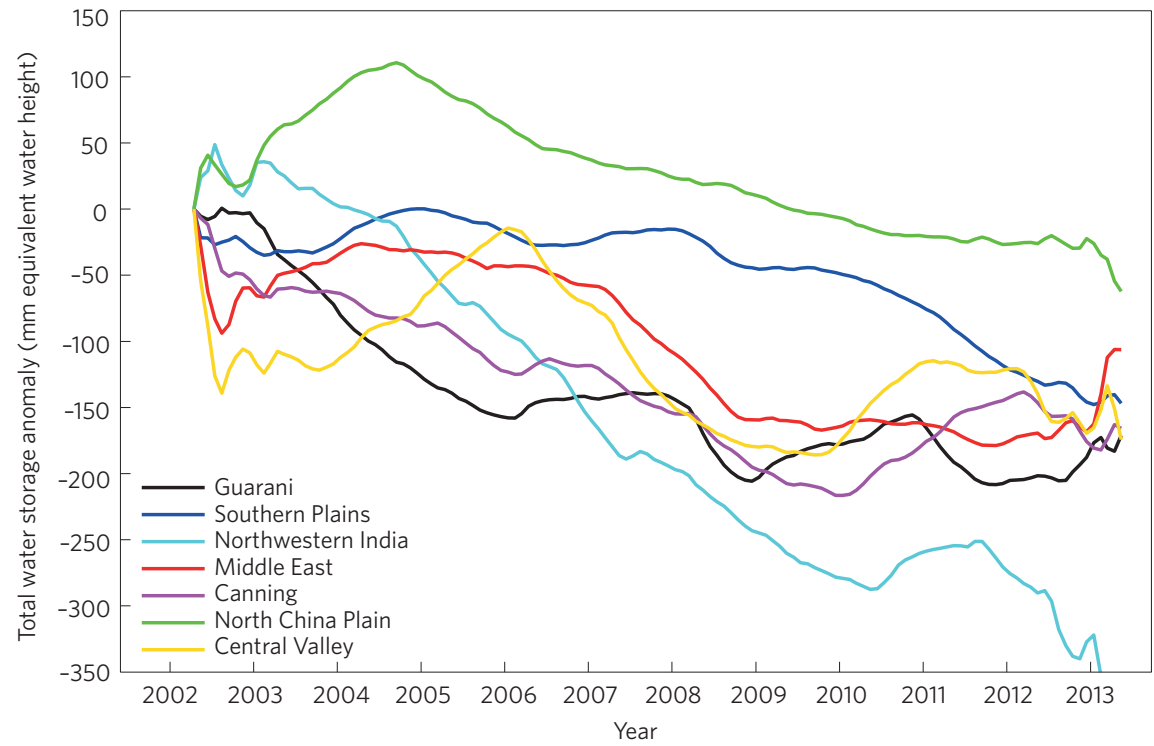

Figure 2 | Water storage declines (mm equivalent water height) in several of the world's major aquifers in Earth's arid and semi-arid mid-latitudes, derived from the NASA GRACE satellite mission. The monthly storage changes are shown as anomalies for the period April 2002-May 2013, with 24-month smoothing. Image: J. T. Reager, NASA Jet Propulsion Laboratory, California Institute of Technology, USA.

environment or other human uses such as municipalities, energy production, industry and economic growth. Pioneering research and development activities in Israel provide several encouraging examples of the potential for greatly increased savings in agricultural water use.

Second, very few major aquifers have been thoroughly explored in the manner of oil reservoirs. As a result, the absolute volume of groundwater residing beneath the land surface remains unknown. Most published estimates of groundwater availability are based on very coarse assumptions regarding aquifer thickness and porosity, and not on actual exploration. Therefore, existing estimates of groundwater storage in individual aquifers vary by several orders of magnitude, so that the uncertainties in available groundwater supplies, by aquifer and globally, are unacceptably high ${ }^{18}$. A hydrogeological exploration of the world's major aquifers that identifies the total amount of groundwater stored, how its quality changes with depth and that fully characterizes their properties is long overdue.

Third, surface and groundwater must be managed conjunctively, as 'one water'. Treating them as disconnected entities, a historical result of limited knowledge of hydrological systems, is no longer scientifically justifiable ${ }^{19}$. It is now well understood that groundwater depletion leads to streamflow depletion, and that excessive streamflow diversions limit groundwater recharge ${ }^{20}$. Many of the world's largest rivers, for example, the Colorado, Indus, Murray and Yellow rivers, no longer reach the ocean, because of excessive water use and overallocation, including overpumping of groundwater ${ }^{21}$.

Fourth, both groundwater levels and withdrawals must be measured and reported, and importantly, these data shared across political boundaries. Effective resource management of transboundary aquifers is otherwise impossible. Policies of data denial, whether between cities, states or nations, are being rendered obsolete by advances in satellite remote sensing. Satellites can now effectively monitor groundwater storage changes at scales that are critical for transboundary water management ${ }^{3,4,10-12,18,21}$, so little benefit remains from continued data withholding. Platforms for sharing such new measurements are already in place ${ }^{20}$ and their use should be required by the United Nations.

Fifth, the recognition of groundwater as a critical element of national and international water supplies is of fundamental importance, both within and between nations. While interstate and international agreements for sharing surface waters in rivers and lakes are plentiful ${ }^{22}$, those for groundwater are not ${ }^{23}$. An unfortunate modern reality is that the global civil and policy infrastructure required to peaceably share groundwater across political boundaries is not yet in place. 
Recent studies of the Colorado River ${ }^{21}$ basin in the western United States and of the Tigris and Euphrates river basins of the Middle East ${ }^{12}$ have exposed excessive rates of groundwater depletion resulting from a lack of intra- or international oversight. The recent multilateral agreement for the management of South America's Guarani Aquifer ${ }^{24}$ is an important example of accord that can result from open dialogue on joint use and management of shared groundwater resources.

The consequences of inaction on these steps are significant, and will expose just how deeply the global economy, geopolitics and the water-energy-food nexus are intertwined. Vanishing groundwater will translate into major declines in agricultural productivity and energy production, with the potential for skyrocketing food prices and profound economic and political ramifications.

Further declines in groundwater availability may well trigger more civil uprising and international violent conflict in the already water-stressed regions of the world, and new conflict in others ${ }^{25}$. From North Africa to the Middle East to South Asia, regions where it is already common to drill over $2 \mathrm{~km}$ to reach groundwater, it is highly likely that disappearing groundwater could act as a flashpoint for conflict.

Managing the global groundwater crisis will require raising awareness of these critical issues to the level of everyday understanding. The actions outlined above are important steps in that direction. Once elected officials, environmental decision-makers and the general public truly understand the sources of water, and how they are affected by climate change, overuse and population growth, the need for action will be clear. Full appreciation of the importance of groundwater to the global water supply and security is essential for managing this global crisis, and for vastly improving management of all water resources for the generations to come.

\section{J. S. Famiglietti is at the NASA Jet Propulsion Laboratory, California Institute of Technology, Pasadena, California 91109-8099, USA, and the Department of Earth System Science, Department of Civil and Environmental Engineering, University of California, Irvine, California 92697-3011, USA. \\ e-mail: James.Famiglietti@jpl.nasa.gov}

References

1. Siebert, S. et al. Hydrol. Earth Syst. Sci. 14, 1863-1880 (2010).

2. Alley, W. M., Healy, R. W., LaBaugh, J. W. \& Reilly, T. E. Science 296, 1985-1990 (2002).

3. Famiglietti, J. S. et al. Geophys. Res. Lett. 38, L03403 (2011).

4. Rodell, M., Velicogna, I. \& Famiglietti, J. S. Nature 460, 999-1002 (2009).

5. Famiglietti, J. S. \& Rodell, M. Science 340, 1300-1301 (2013).

6. Shah, T., Bhatt, S., Shah, R. K. \& Talati, J. Agric. Water Manage. 95, 1233-1242 (2008)

7. Konikow, L. \& Kendy, E. Hydrogeol. J. 13, 317-320 (2005).

8. Wada, Y. et al. Geophys. Res. Lett. 37, L20402 (2010)
9. Gleeson, T., Wada, Y., Bierkens, M. F. P. \& van Beek, L. P. H. Nature 488, 197-200 (2012)

10. Feng, W. et al. Wat. Resour. Res. 49, 2110-2118 (2013).

11. Scanlon, B. R. et al. Proc. Natl Acad. Sci. USA 109, 9320-9325 (2012).

12. Voss, K. A. et al. Wat. Resour. Res. 49, 904-914 (2013).

13. Trenberth, K. E. Clim. Res. 47, 1-16 (2011).

14. Milly, P. C. D. et al. Science 319, 573-574 (2008).

15. Held, I. M. \& Soden, B. J. J. Clim. 19, 5686-5699 (2006).

16. Jackson, R. B. et al. Ecol. Appl. 11, 1027-1045 (2001).

17. Houghton, J. T., Jenkins, G. J. \& Ephraums, J. J. (eds). Climate Change 1990: The IPCC Scientific Assessment (Cambridge Univ. Press, 1990).

18. Richey, A. S. Stress and Resilience in the World's Largest Aquifer Systems: A GRACE-Based Methodology PhD Dissertation, Univ. California, Irvine (2014).

19. McNutt, M. Science 345, 1543 (2014).

20. Margat, J. \& van der Gun, J. Groundwater Around the World: A Geographic Synopsis (CRC Press, 2013)

21. Castle, S. L. et al. Geophys. Res. Lett. 41, 5904-5911 (2014).

22. Giordano, M. et al. Int. Environ. Agreem. 14, 245-264 (2013).

23. United Nations General Assembly Resolution No. 63/124, The Law of Transboundary Aquifers (United Nations, 2011); www.un.org/en/ga/sixth/66/TransAquifer.html

24. Villar, P. C. \& Ribeiro, W. C. Water Int. 36, 646-660 (2011)

25. De Stefano, L., Edwards, P., de Silva, L. \& Wolf, A. T. Water Policy 12, 871-884 (2010).

Acknowledgements

The research highlighted in the figures and tables was supported by the University of California Office of the President, Multicampus Research Programs and Initiatives and by the NASA GRACE Science Team. Conversations and collaborations with M. Rodell, M-H. Lo, J. T. Reager, K. A. Voss, A. S. Richey, S. L. Castle and R. A. Matthew greatly enriched the material discussed here.

Additional information

The opinions expressed here are the author's and do not represent those of NASA, the Jet Propulsion Laboratory, California Institute of Technology or the University of California, Irvine. 